\title{
CLINICAL DIAGNOSIS OF OCULAR SARCOIDOSIS
}

\author{
P. STAVROU ${ }^{1}$, S. LINTON ${ }^{2}$, D. W. YOUNG ${ }^{2}$ and P. I. MURRAY ${ }^{1}$ \\ Birmingham
}

\begin{abstract}
SUMMARY
Purpose: To assess the value of raised serum angiotensin converting enzyme (ACE) levels in making a clinical diagnosis of ocular sarcoidosis in patients with intraocular inflammation, compatible with sarcoidosis, in whom tissue biopsy is either not practical or not possible.

Methods: The ocular manifestations and clinical course of 22 patients with intraocular inflammation compatible with sarcoidosis and elevated ACE level (including 11 patients with abnormal chest radiograph) were compared with those of a group of 18 patients with intraocular inflammation due to biopsy-proven sarcoidosis. The mean follow-up $( \pm$ SD) was $4.5 \pm 3.4$ years in the presumed ocular sarcoidosis group and $7.8 \pm \mathbf{5 . 3}$ years in the biopsy-proven sarcoidosis group.

Results: There was no difference in sex, race and age distribution between the two groups. No statistically significant difference could be found between the ocular manifestations seen in each group. The most common finding was retinal vasculitis with panuveitis, seen in $86.4 \%$ of the presumed ocular sarcoidosis group and in $83.3 \%$ of the biopsy-proven sarcoidosis group. Conclusions: These results suggest that intraocular inflammation compatible with sarcoidosis in conjunction with raised ACE levels would be accordant with a diagnosis of sarcoidosis in patients in whom histological diagnosis is either not practical or not possible.
\end{abstract}

Sarcoidosis is a multisystem granulomatous disorder of unknown aetiology. Although the most common clinical manifestations are bilateral hilar lymphadenopathy, pulmonary infiltration, and skin and eye involvement, ${ }^{1-5}$ its clinical course can be variable and unpredictable and may mimic other diseases. ${ }^{3-9}$ An acute onset with erythema nodosum and hilar tymphadenopathy leads to a benign self-limiting course which can often be shortened by corticosteroid therapy. An insidious onset is usually followed by

From: ${ }^{1}$ Birmingham and Midland Eye Centre; ${ }^{2}$ City Hospital NHS Trust, Birmingham, UK.

Correspondence to: Mr P. I. Murray, PhD, FRCS, FRCOphth, Academic Unit of Ophthalmology, Birmingham and Midland Eye Centre, City Hospital NHS Trust, Dudley Road, Birmingham B18 7QU, UK. Tel: +44(121)-507-6849. Fax: +44 (121)-507 6853. progressive pulmonary fibrosis and organ damage. This may be modified but not necessarily prevented by corticosteroid therapy. Granulomata can be distributed throughout the body without causing significant organ dysfunction or may be concentrated in one or more organs with striking clinical effects. ${ }^{6}$ Ocular involvement is seen in $25-50 \%$ of patients with systemic sarcoidosis ${ }^{3,4-8-10}$ and can precede involvement of other organs by years. $3,4,10,11$

The diagnosis of sarcoidosis is based on the histological evidence of non-caseating epithelioid cell granulomata, in the presence of supporting clinical and/or radiological findings. In patients with sarcoidosis involving only their eyes, histological diagnosis can be difficult. There are conflicting reports regarding the sensitivity of conjunctival biopsy, 2,7,12,13 as intraocular inflammation is not always associated with conjunctival involvement. ${ }^{12}$ Other diagnostic tests for sarcoidosis include serum angiotensin converting enzyme (ACE) levels and gallium scanning. ${ }^{5}{ }^{14-18}$ Raised ACE level has been associated with active sarcoidosis and appears to be a sensitive biochemical marker of disease activity. ${ }^{3,5,14,16,18}$

The aim of this study was to assess the value of raised ACE level in making a clinical diagnosis of ocular sarcoidosis in a group of patients with signs of ocular inflammation compatible with sarcoidosis, in whom tissue biopsy was either not practical or not possible. For this purpose, the ocular manifestations and the extraocular (clinical) course in these patients, known as the presumed ocular sarcoidosis group, were compared with those of a group of patients with ocular inflammation due to biopsy-proven sarcoidosis.

\section{PATIENTS AND METHODS}

The hospital records of all patients with ocular inflammatory disease compatible with sarcoidosis attending the uveitis clinics of the Birmingham and Midlands Eye Hospital between 1990 and 1995, were retrospectively reviewed. All patients had raised serum ACE level and no histological proof of 
Table I. Patient demographics

\begin{tabular}{|c|c|c|c|}
\hline & Presumed ocular sarcoidosis & Biopsy-proven sarcoidosis & $p$ value \\
\hline No. of patients & 22 & 18 & \\
\hline \multicolumn{4}{|l|}{ Sex } \\
\hline Male & $7(32 \%)$ & $9(50 \%)$ & 0.248 \\
\hline Female & $15(68 \%)$ & $9(50 \%)$ & \\
\hline \multicolumn{4}{|l|}{ Race } \\
\hline Caucasian & $7(32 \%)$ & $10(56 \%)$ & 0.15 \\
\hline Afro-Caribbean & $13(59 \%)$ & $7(39 \%)$ & \\
\hline Asian & $2(9 \%)$ & $1(5 \%)$ & \\
\hline Age (years) $\pm S D$ & $37.1 \pm 16.4$ & $46.1 \pm 16.1$ & 0.089 \\
\hline Range & $14-87$ & $21-75$ & \\
\hline Follow-up (years) \pm SD & $4.5 \pm 3.4$ & $7.8 \pm 5.3$ & 0.02 \\
\hline Range & $0.5-12$ & $1.3-19$ & \\
\hline
\end{tabular}

sarcoidosis. Some of these patients had already been under review for several years in other clinics before they were referred to the uveitis clinic. All patients were under the combined care of an ophthalmologist (P.I.M.) and a physician (D.W.Y.)

A total of 22 patients were included in this presumed ocular sarcoidosis group. The mean age $( \pm \mathrm{SD})$ was $37.1 \pm 16.4$ years (range $14-87$ years); 15 patients were female and 7 male. Information regarding type and duration of intraocular inflammation, treatment, initial and latest visual acuity and intraocular operations was recorded. The results of serum ACE, full blood count, VDRL, TPHA, liver function tests (LFT), chest radiograph (CXR) and pulmonary function tests (PFT) were also recorded.

The results of these tests were compared with those in a group of 18 patients, attending the same clinics, with ocular inflammation due to histologically proven sarcoidosis, regardless of serum ACE levels. Of these 18 patients, 12 had positive tissue biopsy and the remainder had a positive Kveim test. The mean age $( \pm S D)$ in this group was $46.1 \pm 16.1$ years (range 21-75 years). Patient demographics for the two groups are summarised in Table I.

The mean follow-up $( \pm S D)$ for the presumed ocular sarcoidosis group was $4.5 \pm 3.4$ years (range $0.5-12$ years), as compared with $7.8 \pm 5.3$ years (range 1.3-19 years) for the biopsy-proven sarcoidosis group.

Statistical analysis was performed using the unpaired two-sample $t$-test (age, follow-up, serum ACE levels) and Wilcoxon rank sum test (sex, race, ocular manifestations).

\section{RESULTS}

Age, sex and race distribution were similar in the two groups, while the follow-up was longer in the biopsyproven sarcoidosis group $(p=0.02)$.

All patients in the presumed ocular sarcoidosis group had raised ACE levels, while serum ACE levels were available in 11 of the 18 patients in the biopsy-proven sarcoidosis group. Of these 11 patients, 8 had raised levels while the remaining 3 had normal levels. The mean ACE levels (SD) were 129 units/l (range 75-290 units/l) for the presumed ocular sarcoidosis group and 157 units/l (range 89-310 units/l) for the biopsy-proven sarcoidosis group. The normal range for ACE in our laboratory is 12-71 units/l for adults and 15-87 units/l for children. No statistically significant difference was found in the mean ACE values in the two groups $(p=0.36)$.

All 22 patients with presumed ocular sarcoidosis had CXR performed, while 18 patients also had PFT. Of the 22 patients, $11(50 \%)$ had CXR changes

Table II. Ocular manifestations

\begin{tabular}{|c|c|c|c|}
\hline & $\begin{array}{l}\text { Presumed ocular sarcoidosis } \\
\qquad(n=22 \text { patients })\end{array}$ & $\begin{array}{l}\text { Biopsy-proven sarcoidosis } \\
(n=18 \text { patients })\end{array}$ & $p$ value \\
\hline Bilateral involvement & $19(86.4 \%)$ & $16(88.8 \%)$ & 0.812 \\
\hline Retinal vasculitis with panuveitis & $19(86.4 \%)$ & $15(83.3 \%)$ & 0.792 \\
\hline Anterior uveitis & $3(13.6 \%)$ & $2(11.1 \%)$ & 0.812 \\
\hline Peripheral hypopigmented spots & $11(50 \%)$ & $12(66.7 \%)$ & 0.295 \\
\hline Iris nodules & $9(40.9 \%)$ & $4(22.2 \%)$ & 0.215 \\
\hline Posterior synechiae & $8(36.4 \%)$ & $6(33.3 \%)$ & 0.843 \\
\hline Cataract & $7(31.8 \%)$ & $6(33.3 \%)$ & 0.919 \\
\hline Glaucoma & $4(18.2 \%)$ & $7(38.9 \%)$ & 0.149 \\
\hline Cystoid macular oedema & $6(27.3 \%)$ & $8(44.4 \%)$ & 0.263 \\
\hline Retinal neovascularisation & 9 & $1(5.6 \%)$ & 0.268 \\
\hline Episcleritis & 0 & $1 \quad(5.6 \%)$ & 0.268 \\
\hline $\mathrm{BRVO}$ & 0 & $1 \quad(5.6 \%)$ & 0.268 \\
\hline Lacrimal gland enlargement & 0 & $1 \quad(5.6 \%)$ & 0.268 \\
\hline Optic disc granuloma & 0 & $1 \quad(5.6 \%)$ & 0.268 \\
\hline Exudative retinal detachment & $1 \quad(4.5 \%)$ & 0 & 0.365 \\
\hline
\end{tabular}

BRVO, branch retinal vein occlusion. 
Table III. Medical treatment

\begin{tabular}{lcc}
\hline Treatment & $\begin{array}{c}\text { Presumed ocular } \\
\text { sarcoidosis } \\
(n=22 \text { patients })\end{array}$ & $\begin{array}{c}\text { Biopsy-proven } \\
\text { sarcoidosis } \\
(n=18 \text { Patients })\end{array}$ \\
\hline TS only & $9(41 \%)$ & $3(17 \%)$ \\
SS only & 0 & $2(11 \%)$ \\
TS + SS & $11(50 \%)$ & $12(67 \%)$ \\
TS + SS + AZA & $2(9 \%)$ & $1(6 \%)$ \\
\hline
\end{tabular}

TS, topical steroids; SS, systemic steroids; AZA, azathioprine.

compatible with sarcoidosis, 9 patients had bilateral hilar lymphadenopathy (BHL), 1 patient had BHL and parenchymal lung disease and 1 patient had extensive parenchymal lung disease without lymphadenopathy. Sixteen of the 18 patients $(88.8 \%)$ tested had abnormal PFT of reduced total lung capacity or impaired gas diffusion, which could be consistent with sarcoidosis. All patients with abnormal CXR had abnormal PFT. In addition, 5 patients with normal CXR had abnormal PFT.

In an attempt for histological proof of sarcoidosis, 3 of the 5 patients with normal CXR and abnormal PFT underwent transbronchial lung biopsy, which was reported as normal. In patients with abnormal CXR and LFT, no attempt for histological proof of sarcoidosis by transbronchial lung biopsy was made. Nevertheless, tissue biopsy was attempted when intraocular material was available. In this way, iris granulomata were found on biopsy from a patient who underwent trabeculectomy and who was subsequently moved into the biopsy-proven sarcoidosis group.

The ocular manifestations in the two groups were similar and are summarised in Table II. All but 3 patients in the presumed ocular sarcoidosis group and 2 patients in the biopsy-proven sarcoidosis group had bilateral involvement. The most common manifestation in the both groups was retinal vasculitis with panuveitis, which occurred in 19 patients $(86.4 \%)$ with presumed ocular sarcoidosis and in 15 patients (83.3\%) with biopsy-proven sarcoidosis. Retinal neovascularisation was seen only in one eye of a patient $(5.6 \%)$ in the biopsy-proven sarcoidosis group. This patient had two episodes of vitreous haemorrhage due to new vessels on the disc. The neovascularisation regressed after panretinal photo-

Table IV. Intraocular surgical procedures

\begin{tabular}{lcc}
\hline & $\begin{array}{c}\text { Presumed ocular } \\
\text { sarcoidosis } \\
(n=44 \text { eyes })\end{array}$ & $\begin{array}{c}\text { Biopsy-proven } \\
\text { sarcoidosis } \\
(n=36 \text { eyes })\end{array}$ \\
\hline ECCE & $1(2.3 \%)$ & 0 \\
Vitreo-lensectomy & $2(4.5 \%)$ & 0 \\
ECCE + IOL & $1(2.3 \%)$ & $5(13.9 \%)$ \\
Trabeculectomy & $2(4.5 \%)$ & $4(11.1 \%)$ \\
Retinal detachment & $1(2.3 \%)$ & 0
\end{tabular}

ECCE, extracapsular cataract extraction, no implant; ECCE + ЮL, extracapsular cataract extraction, implant insertion.
Table V. Extraocular involvement in 22 patients with presumed ocular sarcoidosis

\begin{tabular}{llll}
\hline $\begin{array}{l}\text { No. of } \\
\text { patients }\end{array}$ & Organ & $\begin{array}{c}\text { Time from onset of } \\
\text { ocular involvement }\end{array}$ & \multicolumn{1}{c}{ Evidence } \\
\hline 11 & Lung & At presentation & Abnormal CXR \\
2 & Skin & At presentation & Nodules \\
1 & Liver & At presentation & Abnormal LFT \\
1 & Skin & 4 months & Nodules \\
1 & Lung & 14 months & Abnormal PFT \\
1 & Lung & 18 months & Abnormal PFT \\
1 & Liver & 2 years & Abnormal LFT \\
1 & Skin & 3 years & Nodules \\
1 & Liver & 4 years & Abnormal LFT \\
1 & Lung & 7 years & Abnormal PFT \\
1 & Liver & 12 years & Abnormal LFT \\
\hline
\end{tabular}

CXR, chest radiograph; LFT, liver function tests; PFT, pulmonary function tests.

coagulation and addition of azathioprine to the systemic steroids.

Peripheral punched-out chorioretinal lesions were seen in 11 patients $(50 \%)$ with presumed ocular sarcoidosis and in 12 patients $(66.7 \%)$ with biopsyproven sarcoidosis. They were more commonly seen in the inferior equatorial area, although rarely they affected the posterior pole.

The medical treatment required to control the intraocular inflammation and/or the systemic symptoms in the two groups is summarised in Table III. Eleven of the 22 patients $(50 \%)$ with presumed ocular sarcoidosis and 12 of the 18 patient (67\%) with biopsy-proven sarcoidosis required long-term systemic steroids. Two patients with presumed ocular sarcoidosis and 1 patient with biopsy-proven sarcoidosis required additional immunosuppression (azathioprine) due to failure of systemic steroids or steroid-induced side-effects. Surgical intervention was required in 6 of 44 eyes in the presumed ocular sarcoidosis group and in 9 of 36 eyes in the biopsyproven group. The intraocular procedures performed are documented in Table IV.

Severe permanent visual loss (visual acuity $<6 / 60$ ) was noted in 3 of the 44 eyes $(6.8 \%)$ in the presumed

Table VI. Extraocular involvement in 18 patients with biopsyproven sarcoidosis

\begin{tabular}{llll}
\hline $\begin{array}{l}\text { No. of } \\
\text { patients }\end{array}$ & Organ & $\begin{array}{l}\text { Time from onset of } \\
\text { ocular involvement }\end{array}$ & \multicolumn{1}{c}{ Evidence } \\
\hline 1 & Skin & $\begin{array}{l}\text { 1.5 years prior } \\
\text { to ocular involvement }\end{array}$ & Nodules \\
9 & Lung & $\begin{array}{l}\text { At presentation } \\
\text { At presentation }\end{array}$ & $\begin{array}{l}\text { Abnormal CXR } \\
\text { Nodules }\end{array}$ \\
2 & Skin & Anlargement, \\
2 & Lymph & At presentation & $\begin{array}{l}\text { positive biopsy } \\
1\end{array}$ \\
nodes & Lung & 6 months & Abnormal CXR \\
1 & Lung & 1 year & Abnormal CXR \\
2 & Liver & 2 years & Abnormal LFT \\
1 & CNS & 2 years & Abnormal CT scan \\
1 & Nose & 2 years & Granuloma, \\
& positive biopsy \\
2 & Lung & 3 years & Abnormal CXR \\
\hline
\end{tabular}

CXR, chest radiograph; LFT, liver function tests; CNS, central nervous system. 
ocular sarcoidosis group and in 2 of the 36 eyes $(5.6 \%)$ with biopsy-proven sarcoidosis. One patient in the presumed ocular sarcoidosis group had bilateral severe visual loss. The causes of visual loss were chronic macular oedema in 3 eyes, glaucomatous optic atrophy in 1 eye and recurrent choroidal effusion in another eye.

After a mean follow-up of $4.5 \pm 3.4$ years, 15 of the 22 patients $(68 \%)$ in the presumed ocular sarcoidosis group had involvement of other organs. After a mean follow-up of $7.8 \pm 5.3$ years, 14 of the 18 patients $(77.8 \%)$ in the biopsy-proven sarcoidosis group had involvement of other organs. The lung was the most common organ to be involved in both groups. Details of other organ involvement are given in Tables V and VI.

\section{DISCUSSION}

The clinical course and laboratory manifestations of sarcoidosis remain variable and unpredictable. The results of this study suggest that there is a group of patients in whom sarcoidosis can be limited to the eyes over a long period of time. Establishing a histological diagnosis in these patients has become even more difficult in recent years, because the Kveim test has fallen into disuse. This is because the test is invasive and has been reported abnormal in only $80 \%$ of patients with ocular sarcoidosis. ${ }^{19}$ Furthermore, a negative test does not exclude sarcoidosis and false positive results can occur. ${ }^{1}$ The lack of standardised preparations and the possible health risks posed by the use of human material need also to be considered. ${ }^{5}$

It was not possible to perform a tissue biopsy on all patients in the presumed ocular sarcoidosis group. One of the main reasons was that despite having a number of patients with CXR and PFT abnormalities in this group, these patients were clinically well and denied any symptoms of systemic disease. After the transbronchial biopsies in the 3 patients with normal CXR but abnormal PFT were found to be normal, the physicians involved refused to continue to perform this investigation unless the patients were symptomatic. Furthermore, a number of patients declined the option of a transbronchial biopsy on the grounds that they felt clinically well.

Lieberman et al..$^{20}$ first recognised the association of sarcoidosis with raised serum ACE level and suggested its use as a diagnostic test. ACE levels are elevated in $50-80 \%$ of patients with active sarcoidosis. ${ }^{16-18,20,21}$ Other conditions associated with raised ACE are leprosy, berylliosis, mycobacterial infection, silicosis, histoplasmosis, lymphangiomyomatosis, farmer's lung, Gaucher's disease and primary biliary cirrhosis. Apart from leprosy, tuberculosis and histoplasmosis, all the other conditions are not usually associated with intraocular inflamma- tion. In none of our patients could their ocular manifestations be attributed to any of these three conditions. In sarcoidosis, ACE is probably produced and released by the epithelioid cell granulomata ${ }^{16}$ and its serum levels reflect the total body 'granuloma load', 3,16,17,22-24 If systemic disease is absent, it is possible that 'active' sarcoid granulomata in the eye are producing enough enzyme to result in increased serum levels. Yet there may be granulomata in other areas of the body secreting the enzyme, which cannot be detected by current diagnostic means.

The most common ocular manifestation in the two groups assessed in this study was retinal vasculitis with panuveitis, seen in $86.4 \%$ of patients with presumed ocular sarcoidosis and in $83.3 \%$ of patients with biopsy-proven sarcoidosis. These results differ from those of other studies, which have reported an incidence of $28-84.7 \%$ for anterior uveitis and only $25.3-30 \%$ for posterior uveitis/retinal vasculitis. ${ }^{4.8,9}$ These studies have also reported a higher incidence of ocular involvement in black patients, while in this series only $59 \%$ of patients in the presumed ocular sarcoidosis group and $39 \%$ of patients in the biopsyproven sarcoidosis group were of Afro-Caribbean origin.

It is also interesting that in this study only 1 patient $(5.6 \%)$ in the biopsy-proven sarcoidosis group developed retinal neovascularisation, whilst no patient in the presumed ocular sarcoidosis group showed evidence of this complication. This is in contrast to other studies which reported an incidence of $11-13 \%$ for retinal neovascularisation in patients with retinal vasculitis with panuveitis. ${ }^{4.26}$ It is possible that the high incidence of retinal vasculitis with panuveitis without significant retinal neovascularisation in the groups assessed in this study, is related to the different population studied, the tertiary nature of our uveitis clinic and the treatment regimes used.

Most of the eyes with panuveitis/retinal vasculitis also had peripheral punched-out chorioretinal scars, as reported in other studies. ${ }^{3,9,22,25,26}$ In our series, this finding appears to be twice as common as it was in the study by Spalton and Sanders, ${ }^{26}$ who reported that $36 \%$ of patients with panuveitis due to biopsyproven sarcoidosis had peripheral chorioretinal scars. These are well-defined areas of pigment epithelial atrophy and can vary in size and number amongst different patients. When large and extensive they are easily noted, but when small and few they require careful examination of the fundus, which can be difficult in eyes with vitreous cellular infiltration. Hershey et al..$^{22}$ described that 7 of 10 patients with peripheral punched-out lesions and panuveitis had non-caseating granulomata on non-directed conjunctival biopsy. Four of these 7 patients also had raised serum ACE levels or CXR changes consistent with sarcoidosis and had no symptoms of extraocular 
disease. The pathophysiology of these chorioretinal lesions remains unclear. They appear to evolve over a period of months, from a soft yellowish focus to an area of pigment epithelial atrophy, and they do not appear to contribute to any visual morbidity. Some authors have speculated that they are a sign of granuloma formation in the choroid, and the size of the lesions frequently corresponds to the approximate size of a choroidal vascular lobule. ${ }^{27,28}$ Others, reporting on histopathological material, suggested that the primary lesion is at the level of the retinal pigment epithelium. ${ }^{29}$

In our series, long-term systemic steroids were required in $50 \%$ of patients with presumed ocular sarcoidosis and in $67 \%$ of patients with biopsyproven sarcoidosis. In addition, immunosuppressive treatment was required in a small percentage of patients with uncontrolled inflammation or severe complications of systemic steroids. We share the same experience wtih other authors, ${ }^{10}$ that patients with steroid-resistant ocular sarcoidosis or intolerable steroid-induced side-effects respond well to a combination of azathioprine and low-dose steroids.

Severe visual loss of less than 6/60, in uveitis associated with sarcoidosis, varies from $12.5 \%$ to $19 \%$ and is usually due to chronic macular oedema, glaucoma, epiretinal membrane formation and retinal neovascularisation. ${ }^{3,10,11,26}$ The relatively low percentage of severe visual loss of $6.8 \%$ in the presumed ocular sarcoidosis group and $5.6 \%$ in the biopsy-proven sarcoidosis group in this series may be due to the tertiary nature of our uveitis clinic.

In the presumed ocular sarcoidosis group, 1 of the 3 patients who had an abnormal CXR at presentation did not have radiological evidence of the disease on subsequent tests. His serum ACE had also fallen to normal levels and he was being treated with systemic steroids. In the biopsy-proven sarcoidosis group, 2 of the 5 patients who had an abnormal CXR on presentation also had no radiological evidence of the disease on subsequent tests. The ACE was raised, at the time of repeat CXR, in 1 of these 2 patients and not available in the other patient. Both patients were on systemic steroids at the time of repeat CXR. These findings are in agreement with those of Karma et al. ${ }^{3}$ who found that patients with sarcoidosis involving the eye and other organs, especially lung, can after long follow-up continue to suffer from ocular inflammation when there is no longer radiological evidence of the systemic disease. In this group of patients raised serum ACE was a useful biochemical marker of disease activity. This finding suggests that when a patient is examined for the first time in such a phase it may be difficult to detect any systemic sarcoid abnormalities that may have been present many years earlier.
Systemic steroids can suppress the inflammatory reaction seen in sarcoidosis and usually cause reduction in the serum ACE levels. In this study, 2 of the 3 patients with biopsy-proven sarcoidosis who had normal ACE levels were on systemic steroids at the time of testing, which may have influenced the results. ACE levels were not available for a number of patients in the biopsy-proven group. This may have been due to these patients being diagnosed many years previously at a time when ACE testing was not in widespread use.

Power $e t a l .{ }^{14}$ recently stated that uveitis patients with a raised ACE level and abnormal gallium scan should be considered as having sarcoidosis. They also found a raised ACE level in a small percentage of patients with wide variety of uveitis syndromes not due to sarcoidosis. This differs from our study, where we were only looking at patients whose uveitis was indistinguishable from that seen in patients with biopsy-proven sarcoidosis. It was not our intention to measure ACE levels in every patient attending our uveitis clinics.

In conclusion, the results of this study show that the two groups studied had similar ocular manifestations and extraocular involvement. This suggests that a clinical diagnosis of ocular sarcoidosis can be made in patients with signs of intraocular inflammation compatible with sarcoidosis and raised ACE level, when histological diagnosis is either not practical or not possible. Periodic systemic clinical and laboratory assessment including ACE, CXR, pulmonary and liver function tests is necessary, as these patients are at risk of developing asymptomatic involvement of other organs several years later.

Key words: Sarcoidosis, Intraocular inflammation, Biopsy, Angiotensin converting enzyme, Chest radiograph.

\section{REFERENCES}

1. Stanbury RM, Graham EM, Murray PI. Sarcoidosis. In: Tabbara KF, editor. International ophthalmology clinics, vol 35. Posterior uveitis, part II. Boston: Little, Brown, 1995:123-37.

2. Spaide RF, Ward DL. Conjunctival biopsy in the diagnosis of sarcoidosis. Br J Ophthalmol 1990;74: 469-71.

3. Karma A, Huhti E, Poukkula A. Course and outcome of ocular sarcoidosis. Am J Ophthalmol 1988; 106:467-72.

4. Rothova A, Alberts C, Glasius E, Kijlstra A, Buitenhuis HJ, Breebaart AC. Risk factors for ocular sarcoidosis. Doc Ophthalmol 1989;72:287-96.

5. Kotloff RM, Rossman MD. Sarcoidosis. Immunol Allergy Clin North Am 1992;12:421-49.

6. Benatar SR. Sarcoidosis. Med Int 1990;91:3356-61.

7. Karma A, Taskinen E, Kainulainen H, Partanen M. Phenotypes of conjunctival inflammatory cells in sarcoidosis. Br J Ophthalmol 1992;76:101-6.

8. Jabs DA, Johns CJ. Ocular involvement in chronic sarcoidosis. Am J Ophthalmol 1986;102:297-301.

9. Obenauf CD, Shaw HE, Sydnor CF, Klintworth GK. 
Sarcoidosis and its ophthalmic manifestations. Am J Ophthalmol 1978;86:648-55.

10. Akova Y, Foster CS. Cataract surgery in patients with sarcoidosis-associated uveitis. Ophthalmology 1994; 101:473-9.

11. Foster CS. Ocular manifestations of sarcoidosis preceding systemic manifestations. In: Grassi C, Rizzato G, Pozzi E, editors. Sarcoidosis and other granulomatous disorders. Amsterdam: Excerpta Medica, 1988: $177-81$.

12. Nichols CW, Eagle RC, Yanoff M, Menocal NG. Conjunctival biopsy as an aid in the evaluation of the patient with suspected sarcoidosis. Ophthalmology 1980;87:287-91.

13. Forrester JV. Sarcoidosis and inflammatory eye disease. [Editorial]. Br J Ophthalmol 1992;76:193-4.

14. Power WJ, Neves RA, Rodriquez A, Pedroza-Seres M, Foster CS. The value of combined serum angiotensinconverting enzyme and gallium scan in the diagnosis of ocular sarcoidosis. Ophthalmology 1995;102:2007-11.

15. Karma A, Poukkula AA, Ruokonen AO. Assessment of activity of ocular sarcoidosis by gallium scanning. Br J Ophthalmol 1987;71:361-7.

16. Weinreb RN, Barth R, Kimura SJ. Limited gallium scans and angiotensin converting enzyme in granulomatous uveitis. Ophthalmology 1980;87:202-9.

17. Weinreb RN, Kimura SJ. Uveitis associated with sarcoidosis and angiotensin converting enzyme. Am J Ophthalmol 1980;89:180-5.

18. Dodds EM, Lowder CY, Meisler DM. Presumptive ocular sarcoidosis. [Abstract]. American Uveitis Society Meeting. Ocul Immunol Inflamm 1995;3:273.
19. James DJ, Neville E, Langley DA. Ocular sarcoidosis. Trans Ophthalmol Soc UK 1976;96:133-9.

20. Lieberman J, Nosol A, Schlessner LA, Sastre-Foken A. Serum angiotensin converting enzyme for diagnosis and therapeutic evaluation of sarcoidosis. Am Rev Respir Dis 1979;120:329.

21. DeRemee RA, Rohrbach MS. Serum angiotensinconverting enzyme activity in evaluating the clinical course of sarcoidosis. Ann Intern Med 1980;92:361.

22. Hershey JM, Pulido JS, Folberg R, Folk JC, Massicotte SJ. Non-caseating conjunctival granulomas in patients with multifocal choroiditis and panuveitis. Ophthalmology 1994;101:596-601.

23. Nosal A, Schleissner LA, Mishkin FS, Lieberman J. Angiotensin converting enzyme in noninvasive evaluation of sarcoidosis. Ann Intern Med 1979;90:328-31.

24. Baarsma GS, La Hey E, Glasius E, Vries J, Kijlstra A. The predictive value of serum angiotensin converting enzyme and lysozyme in the diagnosis of ocular sarcoidosis. Am J Ophthalmol 1987;104:211-17.

25. Chumbley LC, Kearns TP. Retinopathy of sarcoidosis. Am J Ophthalmol 1972;73:123-31.

26. Spalton DJ, Sanders MD. Fundus changes in histologically confirmed sarcoidosis. $\mathrm{Br} \mathrm{J}$ Ophthalmol 1981;65:348-58.

27. Franschetti A, Babel J. La chorioretinite en 'taches de bougie' manifestation de les maladie de BesnierBoeck. Ophthalmologica 1949;118:701-10.

28. Laval J. Ocular sarcoidosis. Am J Ophthalmol 1952;35:551-4.

29. Gass JDM, Olson CL. Sarcoidosis with optic nerve involvement. Arch Ophthalmol 1976;94:945-50. 